\title{
The association between hope, anxiety, depression, coping strategies and perceived social support in patients with chronic kidney disease
}

\author{
Bengu Yucens $^{1 \oplus}$, Vahap Ozan Kotan ${ }^{2}$, Nihal Ozkayar ${ }^{3 \oplus}$, Zeynep Kotan ${ }^{4}$, Rabia Yuksel $^{5 \oplus}$, Senol Bayram ${ }^{5}$, \\ Fatih Dede ${ }^{6 \odot}$, Erol Goka ${ }^{5}$

\begin{abstract}
'Afyonkarahisar Health Sciences University, Faculty of Medicine, Department of Psychiatry, Afyonkarahisar - Turkey ${ }^{2}$ Başkent University, Faculty of Medicine, Department of Psychiatry, Ankara - Turkey ${ }^{3}$ Hitit University, Faculty of Medicine, Department of Nephrology, Corum - Turkey ${ }^{4}$ Dr. Abdurrahman Yurtaslan Ankara Oncology Training and Research Hospital, Department of Psychiatry, Ankara - Turkey ${ }^{5}$ Ankara Numune Training and Research Hospital, Department of Psychiatry, Ankara - Turkey
\end{abstract} \\ ${ }^{6}$ Ankara Numune Training and Research Hospital, Department of Nephrology, Ankara - Turkey
}

\begin{abstract}
Objective: Patients with chronic kidney disease (CKD) may experience psychiatric problems while having to cope with the various characteristics of the disease. Identifying the level of hope, coping strategies, and perceived social support may provide valuable information to improve treatment plans and the response to treatment. This study aimed to evaluate the association between hope, anxiety, depression, coping strategies, and perceived social support in patients with CKD.

Method: A total of 65 grade 3 or 4 CKD patients and a healthy control group (51 volunteers) with matched baseline sociodemographic characteristics were included. The participants were evaluated using a sociodemographic data form, the Herth Hope Scale (HHS), Hospital Anxiety Depression Scale (HADS), COPE Inventory, and the Multidimensional Scale of Perceived Social Support (MSPSS).

Results: The level of hope was lower, depression scores were higher and non-functional coping strategies were observed more often in patients with CKD compared to the healthy control group. In multiple linear regression analysis, anxiety and depression levels were found to have a negative effect and perceived social support by the family a positive effect on the level of hope in patients with CKD.
\end{abstract}

Conclusion: Anxiety, depression, and perceived social support by the family predict the hope level of patients with CKD. A multidisciplinary approach including psychiatric consultation should be adopted in the treatment of patients with CKD as hope plays an important role in treatment compliance.

Keywords: Anxiety, chronic kidney disease, depression, hope, social support.

\section{INTRODUCTION}

Chronic kidney disease (CKD) is a life-threatening condition affecting $8 \%-16 \%$ of the world population, leading to a loss of physical function and labor capacity as well as various complications; it can be encountered in almost every age group, particularly in young adults (1). CKD is defined by a decreased glomerular filtration

How to cite this article: Yucens B, Kotan VO, Ozkayar N, Kotan Z, Yuksel R, Bayram S, Dede F, Goka E. The Association Between Hope, Anxiety, Depression, Coping Strategies and Perceived Social Support in Patients with Chronic Kidney Disease. Dusunen Adam The Journal of Psychiatry and Neurological Sciences 2019;32:43-51.

Correspondence: Bengu Yucens, Afyonkarahisar Health Sciences University, Faculty of Medicine, Department of Psychiatry, Afyonkarahisar, Turkey Phone: +90 272440304 E-mail: dr.bengubaz@yahoo.com

Received: October 11, 2018; Revised: October 27, 2018; Accepted: December 18, 2018 
rate $<60 \mathrm{~mL} / \mathrm{min} / 1.73 \mathrm{~m}^{2}$ for a period of at least 3 months (2). Not only does CKD cause limitations in many areas, such as physical activity, nutrition, fluid intake, etc., but the knowledge that in the foreseeable future certain challenging processes such as dialysis or renal transplantation may be experienced creates additional stress for the patients. Possible results are grief, lack of interest and activity, concentration problems, appetite and sleep disorders, despair and, in some cases, suicidal thoughts or suicide attempts (3). Anxiety and depression are more common in patients with CKD than in the general population and lead to a greater risk of non-compliance with treatment, a decrease in quality of life, and an increase in hospitalization and mortality rates $(4,5)$.

As one of the most important factors in the cognitive adaptation of individuals with chronic illness, hope may make a difference to both their experiences and the way they go about their lives (6). Snyder (7) suggested that in addition to the active cognitive process concerning a person's belief in the capacity to reach a given target, hope should also include target-driven energy and a positive sense of intent to reach the target. Among patients with end-stage renal disease (ESRD), individuals feeling hopeful tend to cope more easily with dialysis and difficulties in family, work, and social life (3).

'Coping' can be defined as an individual's resistance to events or factors causing stress as well as the entirety of cognitive, emotional, and behavioral responses aimed at withstanding such situations (8). Sociodemographic factors, personality traits, culture, life events, and social support have been shown to influence a person's coping strategies $(9,10)$.

The most important parameter for adapting to fluid restriction in hemodialysis patients has been reported to be the satisfaction with social support (11). Soykan et al. (12) suggested that among patients with ESRD, there was an increased risk of earlier mortality and suicide in those with weak social support. Even though the stressful situation seems to be overwhelming, the sense of being supported allows people to cope with it. Furthermore, social resources can provide the information and guidance necessary to assist in assessing the threat and planning coping strategies (13).

Studies on this issue found in literature have mainly been conducted with patients suffering ESRD. However, to increase treatment compliance, it is of great importance that a psychiatric evaluation of patients with $\mathrm{CKD}$ is made prior to any treatments that might increase the risk of depression and impair the quality of life, such as hemodialysis or peritoneal dialysis. To the best of our knowledge, there are no studies in the literature on the relationship between hope and coping strategies in patients with CKD. The assumptions of this study were that psychological factors such as hope, coping strategies, and perceived social support would differ between healthy individuals and patients with CKD and that there was a relationship between these factors. The aim of this study was to examine the level of hope and the strategies of coping with stress in patients with CKD compared to a healthy control group and to determine the relationship of such traits with anxiety, depression, and perceived social support in patients with CKD.

\section{METHOD}

This cross-sectional study included 65 patients with grade 3 or 4 CKD and 51 healthy volunteers as the control group. The patients with CKD were selected by a random sampling method from the Nephrology Clinic at Ankara Numune Training and Research Hospital. The healthy control subjects were selected among the hospital staff and their relatives. All participants received a psychiatric evaluation including detailed medical and psychiatric history and the Structured Clinical Interview for DSM-IV Axis I Disorders (SCID-I) by a psychiatrist to identify the presence or absence of current psychiatric disorders. The inclusion criteria were as follows: 1. age 18-65 years; 2 . volunteer to participate in the study, and 3. be diagnosed with grade 3 or 4 CKD. The exclusion criteria were: 1 . having alcohol/substance use disorders; 2 . having a hearing/reading impairment preventing them from completing the questionnaires; 3 . having a chronic mental illness, dementia, or mental retardation. The healthy control group had no chronic illnesses or psychiatric disorders and was matched with the study group with respect to age, gender, occupation, monthly income, and marital status. The participants were evaluated with a sociodemographic data form, the Herth Hope Scale (HHS), the COPE Inventory, the Multidimensional Scale of Perceived Social Support (MSPSS), and the Hospital Anxiety Depression Scale (HADS). Approval for the study was obtained from Ankara Numune Training and Research Hospital Ethics Committee, and written informed consent was obtained from all participants after the procedure had been fully explained to them.

\section{Measures}

\section{Structured Clinical Diagnostic Interview for Axis-I Disorders}

This is a semi-structured clinical interview tool that examines the axis I psychiatric disorders according to 
DSM-IV (14). Ozkurkcugil et al. (15) conducted a validity and reliability study for the Turkish version.

\section{Sociodemographic Data Form}

The form was developed by the researchers to collect the sociodemographic data from the participants, including age, gender, marital status, occupation, monthly income, and education level.

\section{Heart Hope Scale (HHS)}

The HHS was developed by Herth (16). In the reliability analyzes performed for samples assessed with the scale, Herth calculated Cronbach's alpha coefficient to be 0.89 for patients with cancer, 0.94 for the elderly, and 0.92 for healthy adults. The instrument is a self-report form that consists of 30 items, with a 4-point Likert-type scale scored from 0-3. The total hope score ranges from 0 to 90 , with higher scores indicating higher levels of hope. The validity and reliability study of the Turkish version of the scale was conducted by Aslan et al. (17).

\section{Multidimensional Scale of Perceived Social Support (MSPSS)}

The MSPSS was developed in 1988 by Zimet et al. (18). The scale is a 12 -item self-report measure of how individuals perceive their social support system, with participants quantifying the support received from family, friends, and significant others. Items on the MSPSS are rated from 1 (very strongly disagree) to 7 (very strongly agree), with a higher score corresponding to a greater perceived social support. Validity and reliability studies for the Turkish version of the MSPSS were performed by Eker et al. (19) in 2001.

\section{The COPE Inventory}

The COPE Inventory was developed in 1989 by Carver et al. (20). Turkish reliability and validity studies of the inventory were performed in 2005 by Agargun et al. (21). The inventory is a self-report scale consisting of 60 questions and 15 subscales. Each subscale includes 4 questions scored from 1 to 4 . The 15 coping strategies or subscales are as follows: (1) Positive reinterpretation and growth; (2) Mental disengagement; (3) Focus on and venting of emotions; (4) Use of instrumental social support; (5) Active coping; (6) Denial; (7) Religious coping; (8) Humor; (9) Behavioral disengagement; (10) Restraint; (11) Use of emotional social support; (12) Substance use; (13) Acceptance; (14) Suppression of competing activities; (15) Planning. These 15 subscales are grouped under 3 main scale headings: (1) Problem- focused coping (active coping, planning, restraint, use of instrumental social support, suppression of competing activities); (2) Emotion-focused coping (positive reinterpretation, religious coping, humor, acceptance, use of emotional social support); (3) Nonfunctional coping (focus on and venting of emotions, denial, behavioral disengagement, mental disengagement, substance use) (20).

\section{Hospital Anxiety and Depression Scale (HADS)}

The HADS was developed in 1983 by Zigmond et al. (22). The scale is a reliable self-assessment measure used to identify the level of depression and anxiety in patients with physical illnesses and those referred to primary health care. The scale consists of 14 items, each of which is scored from 0 to 3 . Each subscale (anxiety and depression) score is between 0 and 21 . The cutoff score for the anxiety (HADS-A) and depression (HADS-D) subscales of the Turkish version of HADS were found to be 10 and 7, respectively (23).

\section{Statistical Analysis}

The study employed SPSS 20.0 software (IBM Inc., Chicago, IL, USA) for statistical analyses and the G Power 3.1.9.2 package for power analysis. Once the descriptive measures were calculated, both the categorical and the numerical variables were presented in tables using frequency and percentage ratios and mean \pm standard deviation (SD) values, respectively. Kolmogorov-Smirnov analysis found the numerical variables not to conform to a normal distribution. Comparisons of two independent groups were made using the Mann-Whitney $U$ test and comparisons of multiple groups with the Kruskal-Wallis test. The relationships between categorical variables were determined using Chi-square analysis, and relationships between numerical variables were identified through Spearman's Rho correlation analysis method. Models were constructed using stepwise multiple linear regression analysis to determine the variables affecting the level of hope. In all the analyses made, the type-I error value was set to $5 \%$, and a value of $\mathrm{p}<0.05$ was considered statistically significant.

\section{RESULTS}

The study used a cross-sectional survey design. To determine the sample size, a power analysis was made based on the scores of hope and of coping strategies obtained in preliminary studies. As a result of the test 
performed employing an error margin of $5 \%$, an effect size of 0.54 , and a power size of 0.85 for comparison of two independent groups, the number of participants required for each group was found to be 56 . During the time specified for the study, however, a higher number of patients and healthy people were reached in order to increase the power. A total of 116 participants were surveyed within the study, of whom $56 \%(n=65)$ were patients with CKD and $44 \%(n=51)$ were healthy control subjects. Fifty-five of the patients with CKD had comorbid medical diagnoses such as hypertension/ diabetes/coronary artery disease $(n=48)$, an immunological disease $(n=3)$, or polycystic kidney disease $(n=4)$. Forty-seven point seven per cent $(n=31)$ of the patients with CKD were grade 3 and $52.3 \%$ $(\mathrm{n}=34)$ were grade 4 .

The mean age was $48.78 \pm 10.38$ years in the CKD group and $51.73 \pm 8.44$ years in the healthy control group. No significant difference was determined between the CKD and the healthy control groups in terms of sociodemographic features $(p>0.05)$. The familial history of kidney disease $(p=0.009)$ and a history of psychiatric treatment $(\mathrm{p}=0.011)$ were significantly higher in the CKD group. The sociodemographic features of the CKD group and the control group are shown in Table 1.

The HHS score was lower $(\mathrm{p}<0.001)$ and HADS-D score was higher $(\mathrm{p}<0.001)$ in the CKD group compared to the healthy control group. There was no significant difference between the groups in terms of the HADS-A, MSPSS total score and its subscales, and the scores of perceived social support from family, friends and a specific person (Table 2).

Within the COPE subscales, no significant difference was determined between the groups in respect of any item $(p>0.05)$. The more commonly used coping strategies of the CKD group, though not at a statistically significant level, appeared to be 'focus on and venting of emotions,' 'religious coping,' 'use of instrumental social support,' 'denial,' 'humor,' 'behavioral disengagement,' 'restraint,' 'use of emotional social support,' and 'acceptance'. The coping strategies most used by patients with CKD were 'religious coping,' 'positive reinterpretation and growth,' and 'active coping,' respectively. In the control group, the most used coping strategies were listed as 'positive reinterpretation and growth,' 'planning,' and 'religious coping'. The scores of nonfunctional coping strategies were significantly higher in the CKD group than in the healthy group $(\mathrm{p}<0.001)$. No statistically significant difference was determined between the groups with respect to the scores of problem-focused coping and emotion-focused coping ( $\mathrm{p}>0.05)$ (Table 3).

The relationship between gender, grade of the disease, occupation, educational level, and hope, coping strategies, and perceived social support were also investigated. No difference was determined between the genders with respect to the HHS score $(\mathrm{p}=0.494)$. The scores of perceived social support from the family were determined to be higher in males $(p=0.046)$. Neither the hope score $(p=0.238)$ nor the problem-focused $(p=0.441)$, emotion-focused $(\mathrm{p}=0.132)$ and non-functional $(\mathrm{p}=0.294)$ coping strategies differed according to educational level. There was no significant difference between grade 3 and 4 CKD in terms of hope level $(\mathrm{p}=0.095)$ and problem-focused, emotion-focused, non-functional coping strategies (respectively, $\mathrm{p}=0.731, \mathrm{p}=0.451$, $\mathrm{p}=0.177)$. No significant correlations were encountered between age and hope $(\mathrm{p}=0.519)$, perceived social support $(\mathrm{p}=0.944)$, problem-focused non-functional coping strategies $(\mathrm{p}=0.388, \mathrm{p}=0.103$, respectively). In the healthy control group, the effect of age on the hope score $(\mathrm{p}=0.937)$ and problemfocused, emotion-focused, non-functional coping strategies $(\mathrm{p}=0.640, \mathrm{p}=0.971, \mathrm{p}=0.398$, respectively) was not significant.

In the CKD group, the scores of depression $(\mathrm{p}<0.001)$ and anxiety $(\mathrm{p}<0.001)$ were higher and the scores of hope $(p<0.001)$, perceived social support $(\mathrm{p}=0.001)$ and problem-focused coping strategies $(p=0.005)$ were lower among patients with a history of psychiatric treatment compared to patients with no such history. However, there was no statistically significant difference in emotion-focused $(p=0.119)$ and non-functional $(\mathrm{p}=0.076)$ coping strategies.

Linear regression analysis was chosen because these variables act simultaneously. In addition, linear regression gives information about how the dependent variable will change in units of the independent variables. The effect of the scores of other scales on the hope score was calculated by creating individual regression models for the groups. The model created using the stepwise method for the group of patients with CKD was significant $(\mathrm{p}<0.001)$, and the explanatory coefficient was found to be $\mathrm{R}^{2}=0.633$. It was understood that there was no autocorrelation problem, since the Durbin-Watson score was 2.14, no multiple connection problems, as the highest VIF value was 2.12, and no changing variability problem given that the scatter graph between the estimates and the error terms 
Table 1: Participants' sociodemographic features

\begin{tabular}{|c|c|c|c|c|c|c|}
\hline & \multicolumn{2}{|c|}{ CKD group } & \multicolumn{2}{|c|}{ Healthy group } & \multirow[b]{2}{*}{$\chi^{2}$} & \multirow[b]{2}{*}{$\mathbf{p}$} \\
\hline & $\mathbf{n}$ & $\%$ & $\mathbf{n}$ & $\%$ & & \\
\hline \multicolumn{7}{|l|}{ Sex } \\
\hline Male & 30 & 46.2 & 31 & 60.8 & 2.432 & 0.119 \\
\hline Female & 35 & 53.8 & 20 & 39.2 & & \\
\hline History of CKD in the family & 11 & 16.9 & 1 & 2 & 6.898 & $0.009^{*}$ \\
\hline \multicolumn{7}{|l|}{ Occupation } \\
\hline Unemployed & 4 & 6.2 & 0 & & 0.674 & 0.412 \\
\hline Housewife & 28 & 43.1 & 20 & 39.2 & & \\
\hline Worker & 9 & 13.8 & 12 & 23.5 & & \\
\hline Military & 2 & 3.1 & 2 & 19.6 & & \\
\hline Retired & 16 & 24.6 & 10 & 19.6 & & \\
\hline Commercial & 5 & 7.7 & 6 & 11.8 & & \\
\hline Farmer & 1 & 1.5 & 1 & 2 & & \\
\hline \multicolumn{7}{|l|}{ Education } \\
\hline Unschooled & 4 & 6.2 & 0 & & 0.030 & 0.863 \\
\hline Primary school & 25 & 38.5 & 22 & 43.1 & & \\
\hline High school & 25 & 38.5 & 23 & 45.1 & & \\
\hline College/University & 11 & 16.9 & 6 & 11.8 & & \\
\hline \multicolumn{7}{|l|}{ Marital status } \\
\hline Single & 3 & 4.6 & 1 & 2 & 0.087 & 0.769 \\
\hline Married & 58 & 89.2 & 49 & 96.1 & & \\
\hline Divorced & 4 & 6.2 & 1 & 2 & & \\
\hline \multicolumn{7}{|l|}{ Monthly income } \\
\hline 801 to $1500 \mathrm{TL}$ & 23 & 35.4 & 11 & 21.6 & 2.491 & 0.114 \\
\hline 1501 to $2500 \mathrm{TL}$ & 26 & 40 & 23 & 45.1 & & \\
\hline$>2501 \mathrm{TL}$ & 16 & 24.6 & 17 & 33.3 & & \\
\hline \multicolumn{7}{|l|}{ Smoking } \\
\hline Yes & 17 & 26.2 & 14 & 27.5 & 3.241 & 0.072 \\
\hline Quit & 7 & 10.8 & 0 & & & \\
\hline \multicolumn{7}{|l|}{ Alcohol usage } \\
\hline Existing & 2 & 3.1 & 3 & 5.9 & 1.518 & 0.218 \\
\hline Ex-User & 4 & 6.2 & 0 & & & \\
\hline \multirow[t]{2}{*}{ History of psychiatric treatment } & 13 & 20 & 2 & 3.9 & 6.505 & $0.011^{*}$ \\
\hline & Mean & SD & Mean & SD & $\mathbf{z}$ & $\mathbf{p}$ \\
\hline Age (In years) & 48.78 & 10.38 & 51.73 & 8.44 & -1.414 & 0.157 \\
\hline Cigarettes (Packs/year) & 22.93 & 12.81 & 19.00 & 13.58 & -1.156 & 0.248 \\
\hline
\end{tabular}

${ }^{*} \mathrm{p}<0.05, \mathrm{n}$ : number of patients, TL: Turkish Lira, SD: Standard Deviation, CKD: Chronic Kidney Disease

was found to be irrelevant. Anxiety and depression indices were determined to make a negative contribution and perceived social support from the family a positive contribution to the model. An increase of 1 point in the perceived social support from the family was observed to result in an increase of 0.88 points in the hope score, whereas a 1-point increase in the depression and anxiety scores decreased the hope score by 1 point. The data of the coefficients and significance of the models are presented in Table 4. 
Table 2: Hope, anxiety, depression, and perceived social support among CKD and healthy groups

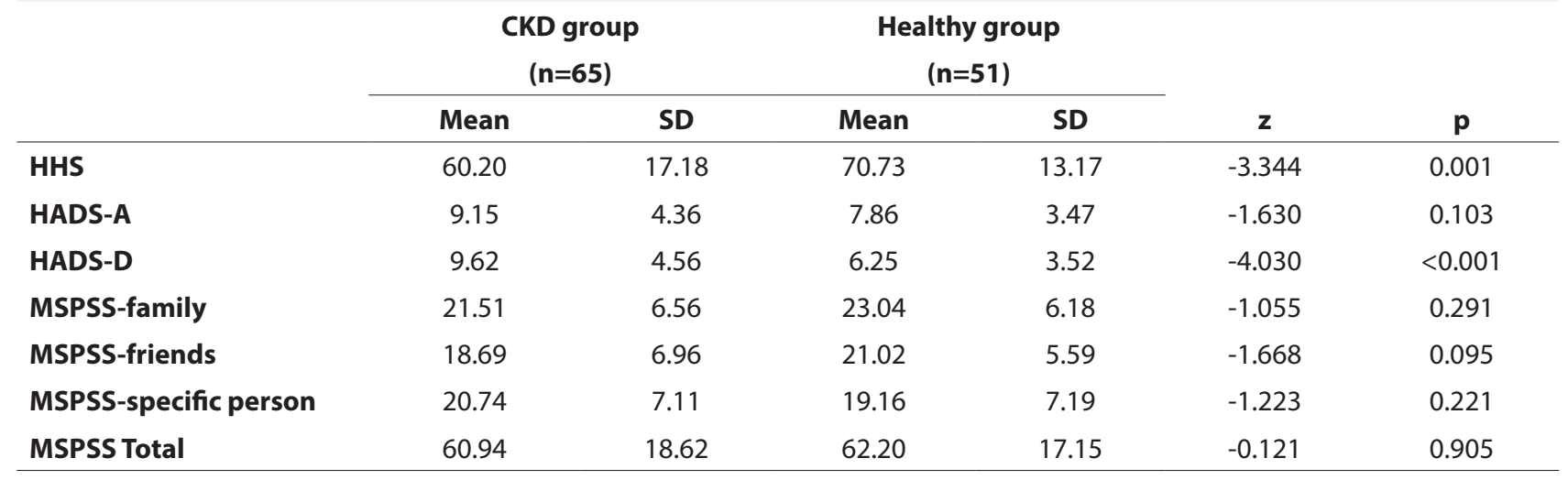

n: number of patients, SD: Standard Deviation, HHS: Herth Hope Scale, HADS-A: Hospital Anxiety Depression Scale-Anxiety Subscale, HADS-D: Hospital Anxiety Depression Scale-Depression Subscale, MSPSS: Multidimensional Scale of Perceived Social Support, CKD: Chronic Kidney Disease

Table 3: Coping strategies in CKD and healthy groups

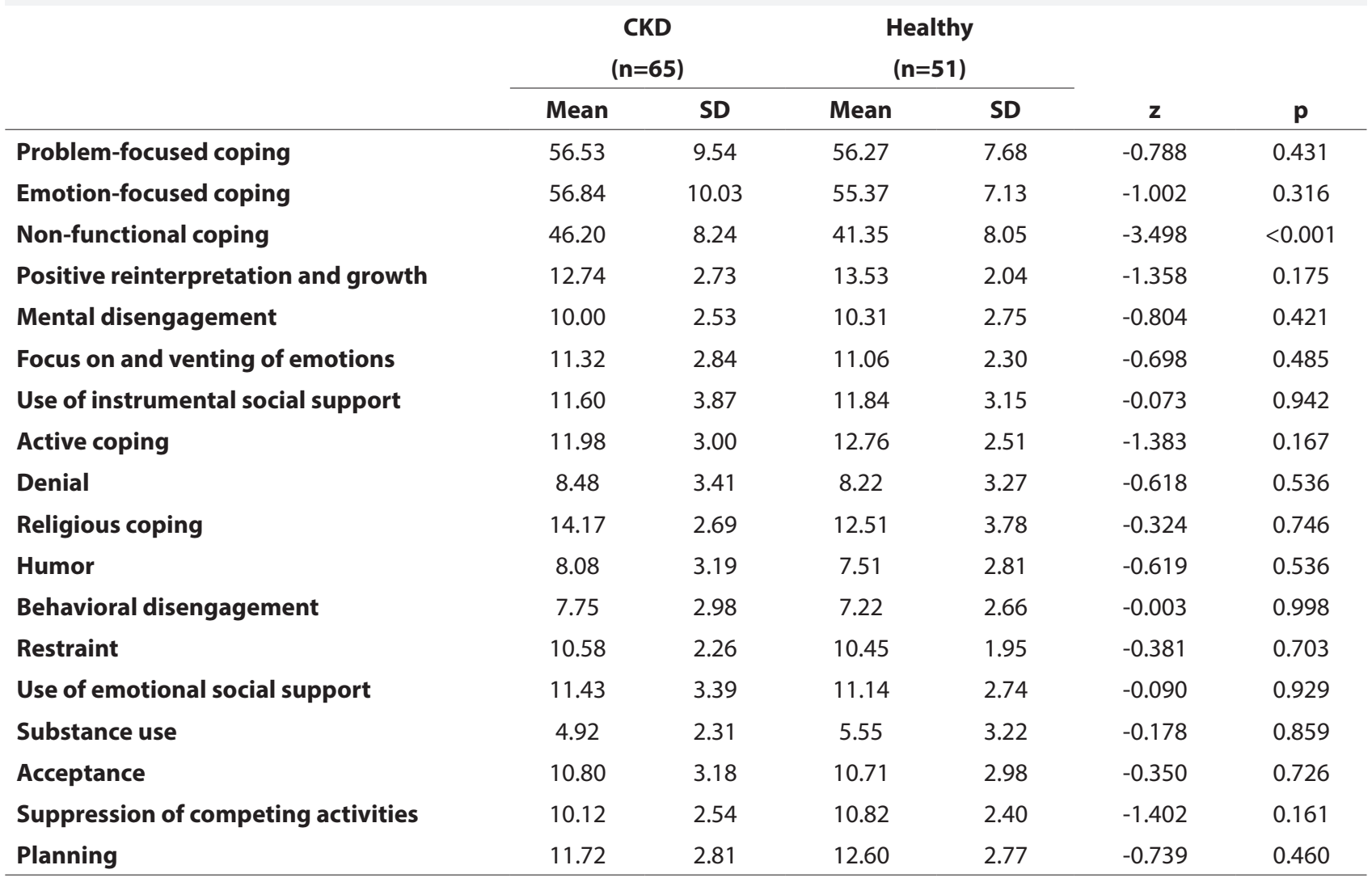

n: number of patients, SD: Standard Deviation, CKD: Chronic Kidney Disease

\section{DISCUSSION}

In the present study, the results demonstrated that patients with CKD are less hopeful and more depressed than healthy individuals also less hopeful the more anxious or depressed they are, and more hopeful when they perceive more social support, as hypothesized. On the other hand, different results emerged regarding the coping strategies. It was found that only the nonfunctional coping strategies were used more in patients with CKD than by healthy individuals, and coping strategies were not a predictor of hopefulness.

Many studies have shown that anxiety and depression symptoms are frequent in patients with ESRD, but there have been few studies of patients with CKD. Baykan et al. (24) reported that according to HADS-D scores, $57.1 \%$ of hemodialysis patients, $53.7 \%$ of peritoneal dialysis patients, and $19.5 \%$ of healthy control subjects were at risk of depression. Findikli et al. (25) found that anxiety and depression scores were 
Table 4: Stepwise multiple linear regression model related to hope level in patients with CKD ( $n=65)$

\begin{tabular}{|c|c|c|c|}
\hline & $\begin{array}{c}\mathrm{R}^{2}=0.633 ; \mathrm{p}<0.001 \\
\text { Beta }\end{array}$ & $\begin{array}{c}D-W=2.143 \\
\text { St. Error }\end{array}$ & $\begin{array}{c}\mathrm{VIF}_{\max }=2.12 \\
\mathrm{p}\end{array}$ \\
\hline Anxiety score & -1.188 & 0.416 & 0.006 \\
\hline Depression score & -1.262 & 0.425 & 0.004 \\
\hline Perceived social support from family & 0.881 & 0.230 & $<0.001$ \\
\hline Emotion-focused coping strategies & & & 0.167 \\
\hline Problem-focused coping strategies & & & 0.129 \\
\hline Non-functional coping strategies & & & 0.613 \\
\hline Perceived social support from friends & & & 0.692 \\
\hline Perceived social support from a specific person & & & 0.229 \\
\hline
\end{tabular}

Dependent variable: Herth Hope Scale Score, n: number of patients, D-W: Durbin-Watson Score, CKD: Chronic Kidney Disease

significantly higher in patients with CKD, and no difference was found between the subgroups in terms of anxiety-depression levels when patients with CKD were divided into subgroups of predialysis, renal transplantation, peritoneal dialysis, and hemodialysis. This suggests that anxiety and depression are common in patients with CKD before dialysis or renal transplantation procedures are started. In the present study, the levels of depression and anxiety were also higher and the levels of hope, perceived social support, and problem-focused coping strategies were lower among patients with a history of psychiatric treatment than in patients with no such history. CKD patients with a history of psychiatric treatment may have some cognitive distortions and therefore may have higher levels of depression and anxiety than patients without a history of psychiatric treatment. This cognitive structure may also be associated with less use of problem-focused coping strategies as it impacts on the patient's affective state and behavioral pattern. In a study of 103 patients receiving hemodialysis, an association was shown between anxiety, and depression with hope, and hope was reported to be a more significant predictor of the psychosocial consequences (anxiety, depression, and quality of life) than age, gender, marital status, duration of illness and social support (3). In the current study, from another point of view, anxiety-depression and perceived social support from the family were found to be significant predictors of the level of hope. These findings suggest that there is a bi-directional relationship between hope and anxiety-depression, and therefore an increase in hope reduces anxiety and depression, and correspondingly an increase in anxiety and depression reduces hope. Whether the relationship is one of cause or effect is not clear, but anxiety, depression, and hope should be taken into account in the assessment of patients with CKD and these characteristics must not be disregarded in the treatment process.
Although previous studies on coping strategies in patients receiving hemodialysis found that these patients were likely to use problem-focused or emotion-focused coping strategies (26-29), Baykan et al. (24) concluded that the use of non-functional coping strategies was higher among patients receiving hemodialysis compared to peritoneal dialysis, which is similar to the findings of the current study. Patients with CKD may be more likely to use non-functional coping strategies, including denial or mental and behavioral disengagement since uncertainty is dominant and they have not yet entered a more specific process such as dialysis or renal transplantation that would facilitate acceptance. In addition, the results of this study regarding coping strategies in CKD patients should be evaluated considering comorbid chronic diseases such as hypertension, diabetes, coronary artery disease, and immunologic diseases. These comorbidities may be potential moderators for a relationship between CKD and coping strategies. Sarisoy et al. (30) found that there was no difference between patients diagnosed with ankylosing spondylitis, another common chronic disease, and a healthy control group in terms of coping strategies. Unlike patients with CKD, patients receiving hemodialysis may be continuously faced with stress related to physical symptoms, dependency on the medical staff, blood vessel problems, and reproductive system functioning. Therefore, different coping strategies will appear in patients receiving hemodialysis compared to patients with CKD.

There is also known to be a dynamic and reciprocal relationship between hope and coping strategies, both of which support each other (28). Hope redresses the balance of both personal and interpersonal events raising concerns during periods of uncertainty in the presence of the disease. From this point on, hope acts as an emotion-focused coping strategy. When the patient makes a minimal contribution to the disease-related 
outcomes, religious belief may support hope, offering a sense of control or employing certain beliefs about holiness (27). Consistent with previous findings in the literature suggesting that cultural factors affect the coping strategies, the most commonly used coping strategies in the current study were religious coping strategies, though the difference was not statistically significant. Coping strategies are expected to be a predictive factor for hope, as non-functional coping strategies are used more frequently in patients with CKD and hope acts as an emotion-focused coping strategy; however, the present study found that coping strategies did not have a predictive effect on hope. This result may be due to the confounding effect of high levels of anxiety and depression on the relationship between coping strategies and hope. There are many potential moderators of the relationship between stress and coping strategies; therefore, such a relationship is complex and these factors need further investigation.

Kimmel et al. (31) suggested that depression arises out of the loss of renal function, well-being, position in the family and at work, time, financial resources and sexual functioning, and eventually, the high rate of depression revealed in numerous studies would not be at all surprising. Turkistani et al. (32) reported that the existence of serious familial problems is an important determinant of anxiety. Therefore, there is a relationship between anxiety, depression, and perceived social support from the family, which might also be associated with hope. In the present study, the patients with CKD tended to be more hopeful when they perceived more social support from the family. While the lack of social support leads to hopelessness, an increased level of hope may promote coping skills. Besides, the scores of perceived social support from the family were found to be higher in males than females in the present study. Women are the more nurturing and supportive sex as a consequence of gender differences acquired in earlier socialization experiences. Due to these features, women may be more likely to take up a caregiver role than men, and men may feel more social support from their family in the case of a chronic disease, such as $\mathrm{CKD}$, requiring care.

In determining the treatment of patients with CKD, it is important to make a selection taking into account the patient's psychiatric conditions in addition to medical necessity and compliance. The clinician may help patients to cope more effectively with chronic illnesses by identifying coping strategies and the associated sources of personal and social support for the patient. Being fully informed about the disease helps patients to gain a sense of control over their experiences and the environment, and to reduce their sensitivity emotions (29). Cognitive behavioral therapy is one of the treatment strategies that has been used effectively to reduce depressive symptoms in patients with CKD $(33,34)$.

This study has investigated the relationship between hope and sociodemographic factors, coping strategies, perceived social support, and some clinical variables in CKD patients. Limitations of the study were the use of self-report measures to detect anxiety and depression, a cross-sectional design, and the inclusion of CKD patients with comorbid chronic diseases such as hypertension and diabetes. There is a need for further, similar prospective studies with follow-up in this area. In spite of these limitations, the findings should help to identify factors related to hope in patients with CKD. Psychological interventions contribute positively to chronic illness processes by decreasing anxiety and depression; therefore, a multidisciplinary approach including psychiatric consultation should be the chosen path in the treatment of patients with CKD. Receiving support from health professionals or support groups may help both the patients themselves and their families and may relieve their discomfort. Counseling-liaison psychiatry can be recommended to deal with the heavy burden brought by CKD as well as the accompanying psychological and social problems.

\begin{tabular}{|l|l|l|}
\hline \multirow{2}{*}{ Contribution Categories } & Author Initials \\
\hline \multirow{3}{*}{ Category 1} & Concept/Design & B.Y., V.O.K., N.O. \\
\cline { 2 - 3 } & Data acquisition & N.O., V.O.K., S.B. \\
\cline { 2 - 3 } & Data analysis/Interpretation & B.Y., R.Y., S.B. \\
\hline \multirow{3}{*}{ Category 2} & Drafting manuscript & B.Y., V.O.K., Z.K. \\
\cline { 2 - 3 } & Critical revision of manuscript & B.Y., V.O.K., E.G. \\
\hline \multirow{2}{*}{ Category 3} & Final approval and accountability & B.Y., V.O.K., Z.K. \\
\hline \multirow{3}{*}{ Other } & Technical or material support & F.D., N.O., R.Y. \\
\cline { 2 - 3 } & Supervision & F.D., E.G., Z.K. \\
\hline
\end{tabular}

Ethics Committee Approval: Approval for the study was obtained from Ankara Numune Training and Research Hospital Ethics Committee.

Informed Consent: Written consent was obtained from the participants.

Peer-review: Externally peer-reviewed.

Conflict of Interest: Authors declared no conflict of interest.

Financial Disclosure: None declared.

\section{REFERENCES}

1. Clarke AL, Young HM, Hull KL, Hudson N, Burton JO, Smith AC. Motivations and barriers to exercise in chronic kidney disease: a qualitative study. Nephrol Dial Transplant 2015; 30:1885-1892. 
2. Levin A, Stevens PE, Bilous RW, Coresh J, De Francisco ALM, De Jong PE, Griffith KE, Hemmelgarn BR, Iseki K, Lamb EJ, Levey AS, Riella MC, Shlipak MG, Wang H, White CT, Winearls CG. Kidney disease: improving global outcomes (KDIGO) CKD work group. KDIGO 2012 clinical practice guideline for the evaluation and management of chronic kidney disease. Kidney Int Suppl 2013; 3:1-150.

3. Billington E, Simpson J, Unwin J, Bray D, Giles D. Does hope predict adjustment to end-stage renal failure and consequent dialysis? Br J Health Psychol 2008; 13:683-699.

4. Palmer SC, Vecchio M, Craig JC, Tonelli M, Johnson DW, Nicolucci A, Pellegrini F, Saglimbene V, Logroscino G, Hedayati SS, Strippoli GFM. Association between depression and death in people with CKD: a meta-analysis of cohort studies. Am J Kidney Dis 2013; 62:493-505.

5. Bautovich A, Katz I, Smith M, Loo CK, Harvey SB. Depression and chronic kidney disease: a review for clinicians. Aust N Z J Psychiatry 2014; 48:530-541.

6. Barnum DD, Snyder CR, Rapoff MA, Mani MM, Thompson R. Hope and social support in psychological adjustment of children who have survived burn injuries and their matched controls. Child Heal Care 1998; 27:15-30.

7. Snyder CR. Hope Theory: rainbows in the Mind. Psychol Inq 2002; 13:249-275.

8. Folkman S, Lazarus RS, Gruen RJ, DeLongis A. Appraisal, coping, health status, and psychological symptoms. J Pers Soc Psychol 1986; 50:571-579.

9. Holahan CJ, Moos RH. Personal and contextual determinants of coping strategies. J Pers Soc Psychol 1987; 52:946-955.

10. Rohde P, Lewinsohn PM, Tilson M, Seeley JR. Dimensionality of coping and its relation to depression. J Pers Soc Psychol 1990; 58:499-511.

11. Pang SK, Ip WY, Chang AM. Psychosocial correlates of fluid compliance among Chinese haemodialysis patients. J Adv Nurs 2001; 35:691-698.

12 Soykan A, Arapaslan B, Kumbasar H. Suicidal behavior, satisfaction with life, and perceived social support in end-stage renal disease. Transplant Proc 2003; 35:1290-1291.

13. Moos RH, Holahan CJ. Dispositional and contextual perspectives on coping: toward an integrative framework. J Clin Psychol 2003; 59:1387-1403.

14. First MB, Spitzer RL, Gibbon M, Williams JBW. User's Guide for the Structured Clinical Interview for DSM-IV Axis I Disorders (SCID-I) Clinician Version. Washington DC: American Psychiatric Press, 1997.

15. Ozkurkcugil A, Aydemir O, Yildiz M, Danaci AE, Koroglu E. Adaptation to Turkish of the Structured Clinical Interview for DSM-IV Axis I Disorders and reliability study. Ilac ve Tedavi Dergisi 1999; 12:233-236 (Turkish).

16. Herth K. Development and refinement of an instrument to measure hope. Sch Inq Nurs Pract 1991; 5:39-51.

17. Aslan O, Sekmen K, Vural H. Hope in nursing students. Hospital Life 2006;1:61-63. (Turkish)
18. Zimet GD, Dahlem NW, Zimet SG, Farley GK. The multidimensional scale of perceived social support. J Pers Assess 1988; 52:30-41.

19. Eker D, Arkar H. Factorial Structure, Validity, and Reliability of the Multidimensional Scale of Perceived Social Support. Turkish Journal of Psychology 1995; 10:45-55. (Turkish)

20. Carver CS, Scheier MF, Weintraub JK. Assessing coping strategies: a theoretically based approach. J Pers Soc Psychol 1989; 56:267283.

21. Agargun MY, Besiroglu L, Kiran UK, Ozer OA, Kara H. The psychometric properties of the COPE inventory in Turkish sample: a preliminary research. Anadolu Psikiyatri Derg 2005; 6:221-226. (Turkish)

22. Zigmond AS, Snaith RP. The hospital anxiety and depression scale. Acta Psychiatr Scand 1983; 67:361-370

23. Aydemir O, Guvenir T, Kuey L, Kultur S. Validity and reliability of [the] Turkish version of [the] Hospital Anxiety and Depression Scale. Turk Psikiyatri Derg 1997; 8:280-287. (Turkish)

24. Baykan H, Yargic I. Depression, anxiety disorders, quality of life and stress coping strategies in hemodialysis and continuous ambulatory peritoneal dialysis patients. Klinik Psikofarmakol Bülteni 2012; 22:167-176.

25. Findikli E, Camkurt MA, Izci F, Yavuz YC, Findikli HA, Altun $\mathrm{H}$, Dogan E. A case-control study on the affective temperament profiles, anxiety and depression levels of patients with chronic renal failure. Journal of Mood Disorders (JMOOD) 2016; 6:133139.

26. Cristovao F. Stress, coping and quality of life among chronic hemodialysis patients. J Ren Care 1999; 25:36-39.

27. Ersoy-Kart M, Guldu O. Vulnerability to stress, perceived social support, and coping styles among chronic hemodialysis patients. Dial Transplant 2005; 34:662-667.

28. Folkman S. Stress, coping, and hope: In Carr BI, Steel, J (editors). Psychological Aspects of Cancer. New York: Springer, 2014, 119-127.

29. Yeh SC, Chou HC. Coping strategies and stressors in patients with hemodialysis. Psychosom Med 2007; 69:182-190.

30. Sarisoy G, Durmus D, Boke O, Canturk F, Sahin AR. Coping with Stress and Body Image in Patients with Ankylosing Spondylitis. Noro Psikiyatr Ars 2014; 51:110-115.

31. Kimmel PL, Thamer M, Richard CM, Ray NF. Psychiatric illness in patients with end-stage renal disease. Am J Med 1998; 105:214-221.

32. Turkistani I, Nuqali A, Badawi M, Taibah O, Alserihy O, Morad $\mathrm{M}$, Kalantan E. The prevalence of anxiety and depression among end-stage renal disease patients on hemodialysis in Saudi Arabia. Ren Fail 2014; 36:1510-1515.

33. Duarte PS, Miyazaki MC, Blay SL, Sesso R. Cognitive-behavioral group therapy is an effective treatment for major depression in hemodialysis patients. Kidney Int 2009; 76:414-421.

34. Cukor D. Use of CBT to treat depression among patients on hemodialysis. Psychiatr Serv 2007; 58:711-712. 